NBER WORKING PAPER SERIES

\title{
THE PRICE TO CONSUMERS OF GENERIC PHARMACEUTICALS: BEYOND THE HEADLINES
}

\author{
Richard G. Frank \\ Andrew Hicks \\ Ernst R. Berndt \\ Working Paper 26120 \\ http://www.nber.org/papers/w26120 \\ NATIONAL BUREAU OF ECONOMIC RESEARCH \\ 1050 Massachusetts Avenue \\ Cambridge, MA 02138 \\ July 2019
}

This research was supported by the National Institute of Aging of the National Institutes of Health under grant number R01 AG043560 to the National Bureau of Economic Research. Frank's effort was also supported by grants from the Laura and John Arnold Foundation and the Harvard Medical School's Dean's Innovation Fund. The views expressed herein are those of the authors and do not necessarily reflect the views of the National Bureau of Economic Research.

NBER working papers are circulated for discussion and comment purposes. They have not been peer-reviewed or been subject to the review by the NBER Board of Directors that accompanies official NBER publications.

(C) 2019 by Richard G. Frank, Andrew Hicks, and Ernst R. Berndt. All rights reserved. Short sections of text, not to exceed two paragraphs, may be quoted without explicit permission provided that full credit, including $\odot$ notice, is given to the source. 
The Price to Consumers of Generic Pharmaceuticals: Beyond the Headlines

Richard G. Frank, Andrew Hicks, and Ernst R. Berndt

NBER Working Paper No. 26120

July 2019

JEL No. I11,L16,L65

\begin{abstract}
Generic drug prices have been the focus of much attention in recent years, with Congressional committees, executive agencies and private organizations all conducting investigations into the pricing patterns for generic drugs. Price spikes for selected old, off-patent drugs have also been widely reported in the media. To place these generic price increases into context, we construct two chained Laspeyres consumer price indexes (CPIs), using the 2007-2016 IBM MarketScan Commercial Claims and Encounters Research Database. The first ("direct out-of-pocket CPI") measures consumers' direct out-of-pocket payments to the dispensing pharmacy, while the second ("total CPI") represents the total revenues received by the dispensing pharmacy - the consumers' direct out-of-pocket payments plus the amount paid to the pharmacy by the insurer on behalf of the consumer.

We find the chained direct-out-of-pocket CPI for generic prescription drugs declines by about 50\% between 2007 and 2016, while the total CPI falls by nearly 80\% over the same time period. The smaller decline in the direct out-of-pocket CPI than in the total CPI is due in part to consumers' increasingly moving away from fixed copayment benefit plans to pure coinsurance or a mixed package of coinsurance and copayments. While consumers are experiencing more cost sharing that in fact shifts more of the drug cost burden on to them, on balance in the US consumers have experienced substantial price declines for generic drugs.

Richard G. Frank

Department of Health Care Policy

Harvard Medical School

180 Longwood Avenue

Boston, MA 02115

and NBER

frank@hcp.med.harvard.edu

Andrew Hicks

Harvard Medical School

hicks@ hcp.med.harvard.edu

Ernst R. Berndt

MIT Sloan School of Management

100 Main Street, E62-533

Cambridge, MA 02142

and NBER

eberndt@mit.edu
\end{abstract}




\begin{abstract}
Context: Generic drug prices have received a great deal of attention in the past few years. Congressional committees, executive agencies and private organizations have all conducted investigations into the pricing patterns for generic drugs. Price spikes for several specific generic drugs have also been widely reported in the media.

Methods: We construct two Laspeyres chained price indexes that capture prices of generic prescription drugs paid by consumers and private health plans. The first reflects direct out of pocket payments made by the consumer to a pharmacy for dispensing a generic prescription drug (“direct out-of-pocket CPI”, and the second the total price received by the pharmacy ("total CPI") comprised of the direct out-of-pocket payment from the consumer plus the price paid to the dispensing pharmacy by the insurer on behalf of the consumer.

Findings: The chained direct out-of-pocket CPI we construct shows a roughly $50 \%$ decline for generic prescription drugs between 2007 and 2016. In addition, between 2007 and 2016 the total CPI for generic prescription drugs fell by nearly $80 \%$.

Conclusions: The U.S. generic prescription pharmaceutical market continues to drive overall prices downward, although pharmacy price declines are not fully passed through to consumers. Our evidence suggests that overall affordability is not the main problem in the generic drug market.
\end{abstract}

Key Words: Prescription drugs; generic drugs; prices; affordability

\title{
I. Introduction
}


Generic drug prices have received a great deal of attention in the past few years. Congressional committees, executive agencies and private organizations have all conducted investigations into the pricing patterns for generic drugs. ${ }^{1}$ Price spikes for certain specific generic drugs have also been widely reported in the media. While these dramatic price increases have appeared with some regularity, they have typically involved drugs with small sales volume. ${ }^{2}$ Recent statistics on pricing trends for generic drugs reported by pharmacy benefit manager Express Scripts and by the U.S.

Government Accountability Office document that for private insurers and Medicare, overall generic prices paid to manufacturers have continued to drift downward. ${ }^{34}$ Even with these reported general price declines, there are on-going concerns about affordability and the dramatic price increases accompanying supply interruptions in the market for generic drugs. Some of these concerns emanate from changes in insurance benefit designs that affect the out-of-pocket costs of health care for consumers, while others involve the perceived exploitation of market power by manufacturers in some parts of the generic drug marketplace. Together, this set of concerns has prompted policy makers to propose actions to make generic drugs more affordable. For example, Senator Elizabeth Warren (D-MA) has proposed creating a publicly owned and operated generic drug maker. $^{5}$

Private health insurers are increasingly offering high deductible health plans, expanding cost sharing for services and shifting costs of health care from insurers to consumers of care. For example, the Kaiser Family Foundation/HRET's annual survey of employer health benefits for 2017 shows a large increase in plans with deductibles of over $\$ 1,000$ since $2012 .{ }^{6}$ More specifically, pharmacy benefits have also expanded the 
cost sharing requirements for consumers. Most cost sharing increases for prescription drugs have been directed to specialty drugs but even generic drugs have been subjected to increases in copayments and deductible provisions. This has the effect of creating more consumer exposure to market prices. Such benefit design changes are experienced by consumers as price changes for health care products and services.

In this paper we focus on generic prices experienced by consumers in private health insurance plans serving private and public employees and their dependents. We report on price indexes constructed from insurance claims paid on behalf of enrollees in large employee sponsored insurance plans. We construct two price indexes that capture prices of generic prescription drugs paid by this segment of the health sector. The first reflects direct out-of-pocket payments made by the consumer to a pharmacy for dispensing a generic prescription drug (“direct out-of-pocket CPI"), and the second the total price received by the pharmacy comprised of the direct out-of- pocket payment from the consumer plus the price paid to the dispensing pharmacy by the insurer on behalf of the consumer; we name this latter price index the "total CPI" We place both these consumer price indexes (CPI) that we construct into the context of other recent analyses of trends in generic prices to offer a more complete view of the price patterns for generic prescription drugs. In addition, we explore changes in cost sharing arrangements in the insured populations studied so as to understand trends in the composition of consumer price indexes for generic drugs.

The paper is organized into five sections. The section following this Introduction provides background on consumer prices and issues in summarizing their trends. The 
third section describes the data used to construct the price indexes. The fourth section presents the price indexes in graphical form and places them in the context of other recently released data on price trends for generic prescription drugs. The final section offers concluding observations.

\section{Assessing Consumer Prices for Generic Drugs}

A consumer price index or CPI is a method of summarizing information on price changes. The policy focus on the pricing patterns for generic drugs demands that summary measures of price trends be available that offer a type of weighted average picture of generic price movements with weights expressing relative quantity proportions of the various generic drugs. Express Scripts, a pharmacy benefit management company and the U.S. GAO have recently reported price indexes for generic drugs. Both indexes focus on the payments made by an insurer to manufacturers for the ingredient cost of generic drugs. As such these price indexes reflect a portion of the total price and do not reflect the net out-of-pocket cost to consumers (or direct consumer out-of-pocket price). Nor do they reflect dispensing fees received by the pharmacy. Thus they do not offer a view of changes in the affordability of generic drugs for consumers. Both sets of indexes show overall declines in generic prices through 2016 and 2015 respectively (more discussion of the results follows below).

In the out-of-pocket and total CPI price indexes we construct, we use principles of the CPI as constructed by the U.S. Bureau of Labor Statistics (BLS), although the BLS does not publish separate brand and generic prescription drug price indexes. We allow for new products to enter the market and construct a so-called chained Laspeyres index. Each 
time series observation is based on a chained Laspeyres index using the following equation:

$$
P_{t_{n}}=\frac{\sum\left(p_{c, t_{1}} \cdot q_{c, t_{0}}\right)}{\sum\left(p_{c, t_{0}} \cdot q_{c, t_{0}}\right)} \times \frac{\sum\left(p_{c, t_{2}} \cdot q_{c, t_{1}}\right)}{\sum\left(p_{c, t_{1}} \cdot q_{c, t_{1}}\right)} \times \ldots \times \frac{\sum\left(p_{c, t_{n}} \cdot q_{c, t_{n-1}}\right)}{\sum\left(p_{c, t_{n-1}} \cdot q_{c, t_{n-1}}\right)}
$$

where $P_{t_{n}}$ is the price index for period $t_{n}$ and $t_{0}$ is a base reference period that anchors the value of the series. $p_{c, t} i s$ the mean price of $\operatorname{drug} c$ in period $t$ and $q_{c, t}$ is the quantity of drug $c$ sold in period $t$. New drugs are excluded from this formula in the first month that they appear in the dataset, and only begin to contribute to the index in the second month they exist in the data, when price and quantity information is available from the previous month for purposes of comparison. Exiting drugs are included in the index for only those months their quantities sold are positive.

While our focus is on prices paid directly by the consumer, we also report two other indexes. The first is the Bureau of Labor Statistics Consumer Price Index for all prescription drugs (“BLS CPI”), an aggregate of brand and generic prescription drug prices reflecting total revenues received by a dispensing pharmacy from the consumer and the insurer. Procedures used by the BLS in constructing their aggregate CPI for prescription drugs are described elsewhere. ${ }^{7}$ The second, our "total generic CPI", is a price index we construct that represents the total revenue received by the dispensing pharmacy for a prescription from both the consumer and the insurer. Both payment sources are included in this index so as to provide context regarding whether changes in consumer prices reflect cost shifts between consumers and insurers versus general price changes. This total CPI is also similar to the prescription drug CPI price index 
constructed by the Bureau of Labor Statistics, although the later encompasses both brand and generic drugs whereas our total CPI covers only generic drugs.

As noted earlier, a variety of important changes in the design of health insurance and its management have occurred that have the potential to affect the relative shares of consumer and insurer responsibilities for final payments for prescription drugs and other medical services. In addition to increases in deductibles and copayments for generic drugs in private insurance plans, there have been other changes in benefit design such as increases in the number of cost sharing tiers and so called copay accumulators. All these tend to increase consumers' out-of-pocket liability, especially for branded specialty drugs. In response to some of these benefit design changes, manufacturers have offered discount coupons that serve to reduce the direct out-of-pocket price to consumers, but these are mostly applied to brand name drugs. There has also been consolidation in the supply chain that includes greater concentration among wholesalers, joint ventures between wholesalers and retailers, and concentration in the market for pharmacy benefit managers. Together these changes have the potential to alter dispensing fees and other transaction costs. Our "total generic CPI" measures the total price paid to the dispensing pharmacy including the ingredient costs, dispensing fees and other costs. It does not take into account the rebates that are paid by manufacturers to pharmacies and pharmacy benefit managers ex post the transactions. By comparison, our direct out-of-pocket CPI tracks only what the consumer pays (all out-of-pocket costs, i.e., deductible, copayment, and coinsurance). 
Finally, we examine changes in cost sharing arrangements in some detail. We do so by documenting how the use of coinsurance and copayments has changed over time and the share of insured beneficiaries affected by those changes. We also focus on the pattern of cost sharing by examining the percentage of generic drug claims that are subject to zero copayments or coinsurance over time. These patterns enable us to offer a richer distributional impact interpretation of the results from our constructed aggregate CPI price indexes.

\section{Data}

The data for our research comes from the IBM MarketScan Commercial Claims and Encounters Research Database for the years 2007-2016. These data include deidentified patient-specific medical inpatient and outpatient claims, outpatient pharmaceutical data and enrollment data for approximately 40 million people annually. The data come from a selection of approximately 350 payers consisting of large employers, health plans, and government and public organizations. The database does not include claims data from patients over age 65 .

The data contain more than 100 million adjudicated generic drug claims annually. Generic drugs were identified through national drug codes (NDCs) and a generic indicator flag contained in the data base. The claims are final and include the total amount paid by all parties as well as out-of-pocket costs paid by the patient to satisfy any copayment, coinsurance or deductible obligations. From these two amounts we are also able to calculate the gross payment made by the insurer to the pharmacy. 


\section{Results}

Recent reports on price movements for generic prescription drugs for privately insured groups and those covered by the Medicare Part D program document sharp declines in generic prices overall. ${ }^{8}$ In the Medicare program there was an overall drop of 60 percentage points from 2010 through 2015. There was a more modest decline of about $10 \%$ for drugs that were generic for the entire period. This is in part because most generic molecules had reached a competitive equilibrium price point prior to the initial observation period. While Medicare represents a different population and somewhat different purchasing arrangements than private insurance, we nevertheless expect the generic market to function in a similar fashion to that faced by privately insured groups. The private insurance experience reported by Express Scripts is the most relevant to the analysis we present. Figure 1 summarizes two Express Scripts price indexes for the period 2008 through 2015 - one for brands, one for generics. Also included is BLS' consumer price index, a market basket of commonly used household goods costing $\$ 100.00$ in 2008. 


\section{Figure 1}

Express Scripts Price Indices Comparison, Absolute (2008-2015)

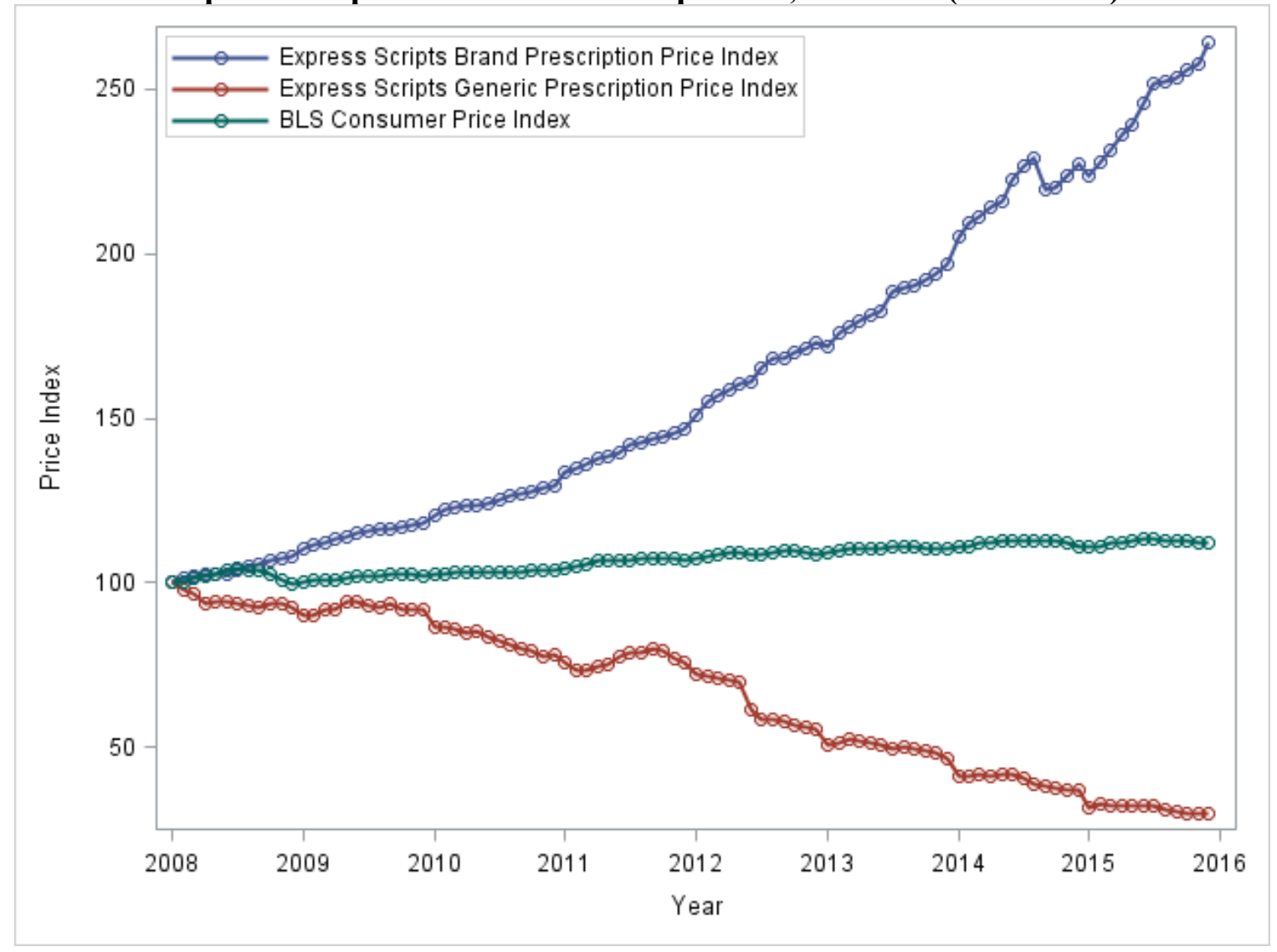

The Express Scripts generic price index shows a more than $70 \%$ decline in the price index during the observation period. This suggests that insurers are paying much less for generic drugs in 2016 than in 2008. Moreover, an increasing number of branded drugs have lost market exclusivity, and the Express Scripts generic price index incorporates the price impacts of these new generic products. It is important to note that because of the so-called generic cliff that occurred around 2012, this index captures competitive adjustments for a large number of newly launched generic products. During this same time period the Express Scripts index for brand name drugs grew by $164 \%$, while the consumer price index increased by about $12 \%$. 
We construct two price indexes using the IBM MarketScan data for the years 2007 through 2017; they appear on Figure 2. The first "out-of-pocket CPI" reflects consumers' out of pocket spending, a true CPI. It is the saw tooth curve on Figure 2. The second is the total price paid by the payer and consumer ("total CPI") and that is the lower curve on Figure 2. To put this into context we scale the indexes to the level of the BLS' CPI for all (brand plus generic) prescription drugs in January 2007 (the BLS' CPI for all prescription drugs is 367 , indexed to 100 in 1982). The BLS' index is included in Figure 2 as the upward sloping curve.

Figure 2

Chained Direct Out of Pocket Consumer Price and Total Price Indexes

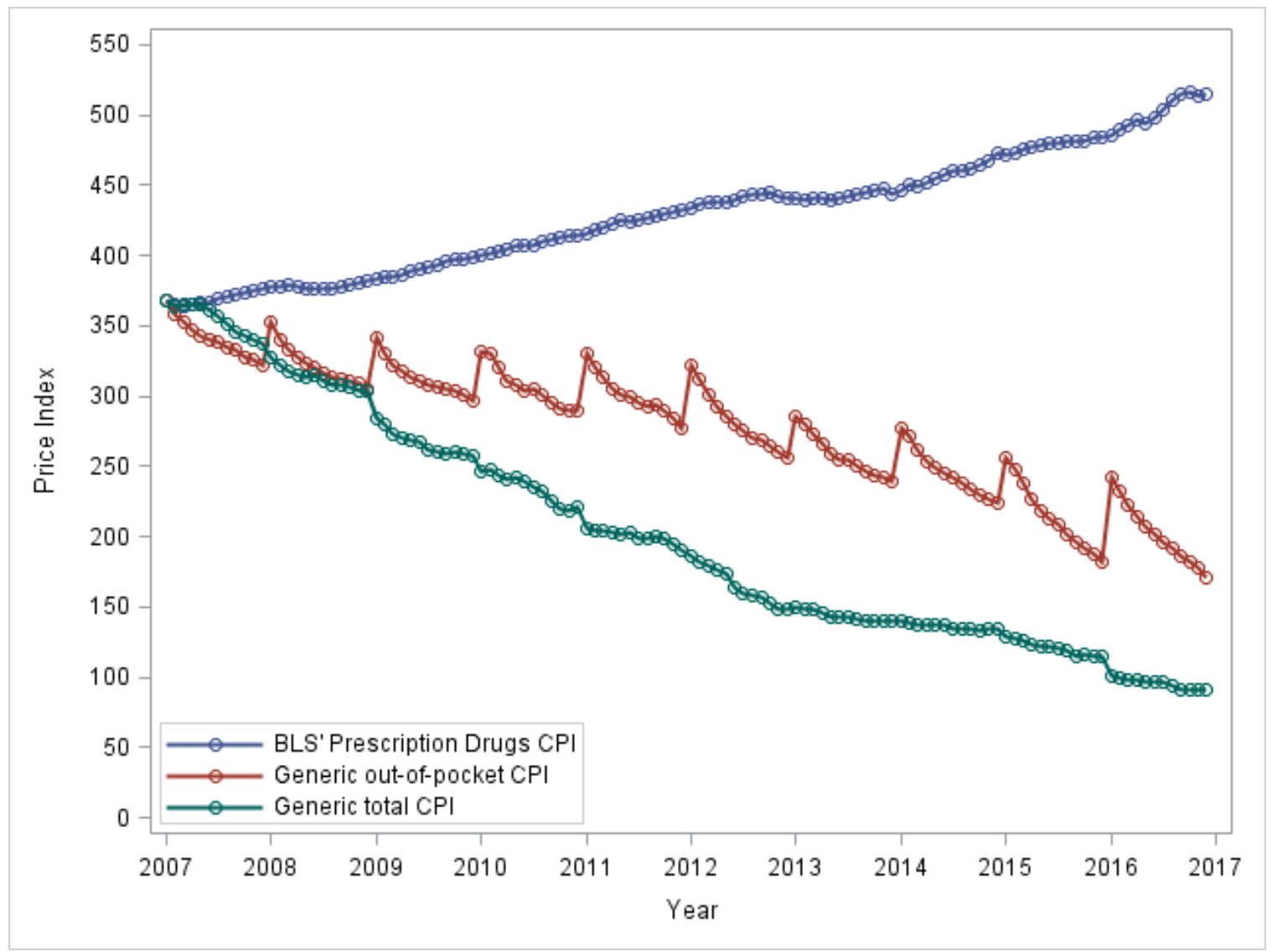


Figure 2 offers several key insights about the direct out-of-pocket prices facing consumers for generic prescription drug products. The first and most important -evidenced by the lowest trend pattern -- is that consumers appear to be benefitting from the overall price reductions for generic drugs reflected in data on payer obligations for generic drug costs. The chained direct out-of-pocket CPI we report (the middle curve in Figure 2) shows a roughly $50 \%$ decline in the out-of-pocket costs for generic prescription drugs between 2007 and 2016. The jagged annual pattern of prices that appears in the Figure reflects the fact that deductibles are typically reset on the first day of the calendar year. Thus, on the first of the year in each calendar year the price to consumers increase as they become responsible for the full cost of the generic prescription and not just the copayment or coinsurance after the deductible threshold is attained. Nevertheless if one tracks just the high "price" points in each year, we observe a decline in the level that the high point reaches each successive year. The graph also suggests that the increases from the prior year's low "price" point to the price at the beginning of each subsequent calendar year has increased somewhat, consistent with observations from benefit design surveys that deductible thresholds have been increasing over time.

Figure 2 highlights the stark contrast between the generic out-of-pocket CPI and the BLS' overall drug CPI (or the Express Scripts CPI). Since 2007 the BLS' overall prescription drug CPI increased about $44 \%$, while the mean monthly out-of-pocket CPI over the 12 months in 2016 was about 58\% less than its value in 2007. Notably, the BLS' CPI has increased quite consistently over the period with a slight slowdown occurring in late 2015 and late 2016 . 
The lowest curve in Figure 2 represents an index for the total price paid by insurers and consumers to dispensing pharmacies for generic prescription drugs, based on our IBM Health MarketScan Commercial Claims and Encounters Research Database. The total CPI curve reveals that the overall price movement for generic drugs has consistently declined since 2007. Notably, between 2007 and 2016 prices for generic prescription drugs fell by nearly $80 \%$. The price reductions since 2013 have been more modest than were the reductions between 2011 and 2013, i.e., the period that covered the generic cliff except for a drop at the beginning of 2016. In considering the change in consumer prices compared to those in the overall price change of generic drugs we observe that it appears that changes in consumer prices have been proportionately smaller. That is, between 2007 and 2016 consumers' out-of-pocket prices fell by roughly $22 \%$ less than total prices paid to pharmacies. Nevertheless, in the most recent three-year period generic prices paid by consumers have seen larger proportional declines especially at the end of the calendar year when coverage is most complete.

We have explored further the differential drop between the total price paid ("total CPI") and consumer out-of-pocket prices ("out-of-pocket CPI") by delving into changes in cost sharing arrangements. Table 1 reports the changing mix of cost sharing arrangements over time as found in the MarketScan claims database. We identify plans where the cost sharing is predominantly coinsurance, copayments or a mix of the two, by share of plan types and share of enrollees. The table shows a notable move away over time from fixed copayment and a greater reliance on pure coinsurance or a mixed package of coinsurance and copayments. Specifically, as seen in the right panel of Table 1, in $200785 \%$ of enrollees were in plans where out-of-pocket costs for generic drugs 
were defined by a fixed copayment. That percentage declined to $57 \%$ by 2016 . This trend coupled with higher deductibles during the 2007-2016 time period explains why out-ofpocket prices appear to have declined less than the prices paid by insurers and patients together.

Table 1

Cost Sharing Arrangements

\begin{tabular}{|c|ccc|ccc|}
\hline & \multicolumn{6}{|c|}{ Coinsurance vs. Co-pay Plans } \\
\cline { 2 - 7 } & \multicolumn{3}{|c|}{ Plan Types } & \multicolumn{3}{c|}{ Percent of enrollees } \\
\hline Year & Coinsurance & Co-pay & Mixed & Coinsurance & Co-pay & Mixed \\
\hline 2007 & $5 \%$ & $83 \%$ & $13 \%$ & $4 \%$ & $85 \%$ & $10 \%$ \\
2008 & $5 \%$ & $83 \%$ & $13 \%$ & $4 \%$ & $81 \%$ & $16 \%$ \\
2009 & $5 \%$ & $81 \%$ & $14 \%$ & $3 \%$ & $70 \%$ & $27 \%$ \\
2010 & $3 \%$ & $80 \%$ & $17 \%$ & $2 \%$ & $71 \%$ & $26 \%$ \\
2011 & $2 \%$ & $80 \%$ & $18 \%$ & $2 \%$ & $66 \%$ & $32 \%$ \\
2012 & $7 \%$ & $77 \%$ & $16 \%$ & $5 \%$ & $83 \%$ & $12 \%$ \\
2013 & $8 \%$ & $72 \%$ & $20 \%$ & $9 \%$ & $75 \%$ & $16 \%$ \\
2014 & $11 \%$ & $60 \%$ & $30 \%$ & $12 \%$ & $59 \%$ & $29 \%$ \\
2015 & $13 \%$ & $54 \%$ & $33 \%$ & $14 \%$ & $58 \%$ & $27 \%$ \\
2016 & $12 \%$ & $52 \%$ & $35 \%$ & $14 \%$ & $57 \%$ & $29 \%$ \\
\hline
\end{tabular}

Figure 3 shows the net effect on the share of the total price of generic drugs paid for out-of-pocket by consumers (i.e., out-of-pocket payment divided by total payment received by pharmacy). Like the earlier out-of-pocket CPI for generic drugs we observe a saw tooth pattern for the percent paid out-of-pocket. We also see that the highest out of pocket price (the first day of each new year) declined from $25 \%$ to about $20 \%$ of the total price. Similarly, the lowest out of pocket price (typically at year end) declined from about $20 \%$ in $2007-2008$ to nearly $10 \%$ at the end of 2016 . Furthermore the underlying data reveals (though not shown in Table 1) that the share of transactions with a zero 
copayment or zero coinsurance out-of-pocket payment has increased from 11\% in 2007 to $30 \%$ in 2016 .

Figure 3

Percent of Total Price Paid Out of Pocket

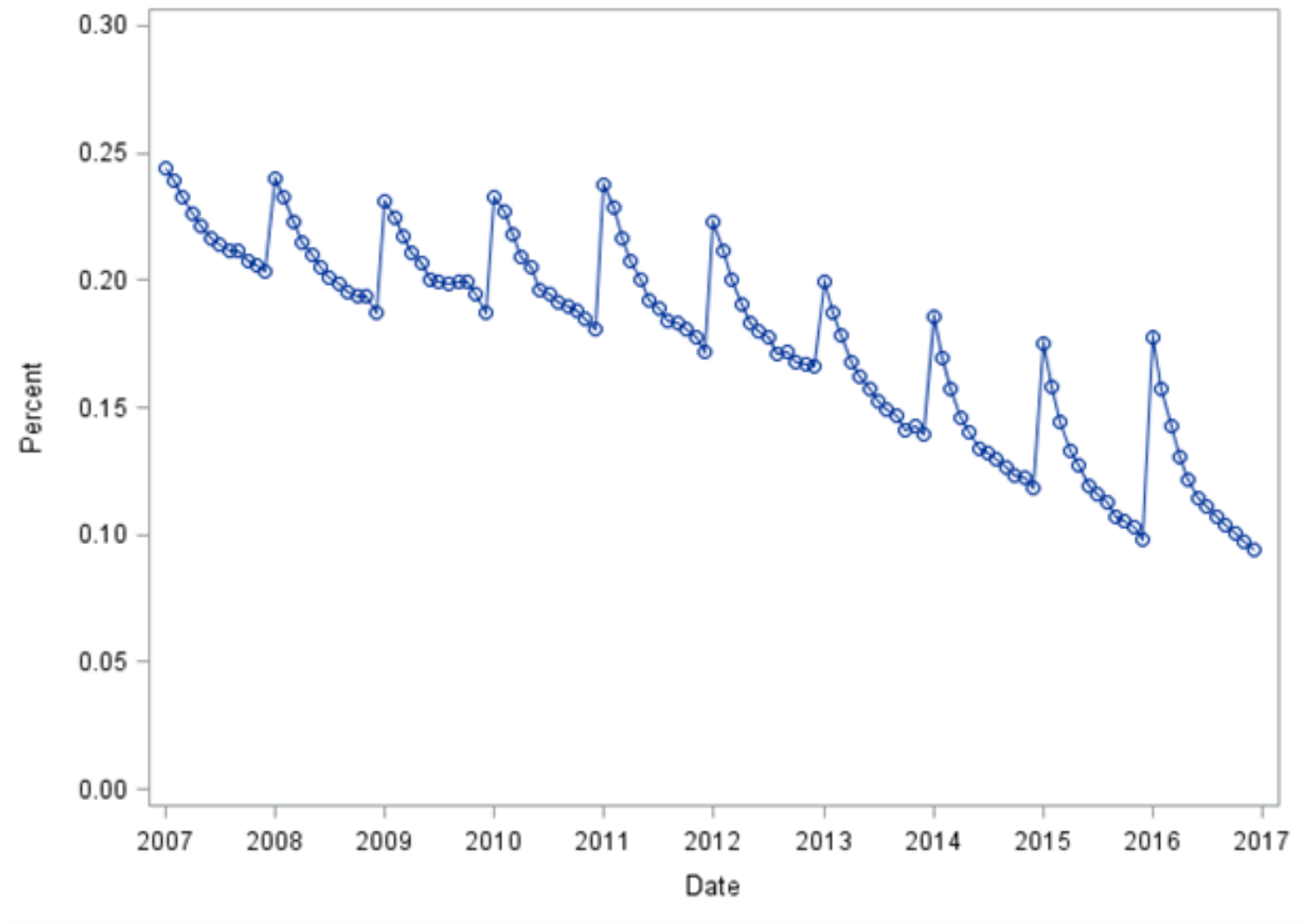

\section{Concluding Observations}

The eye-catching increases in certain generic drug products have drawn attention to generic drugs as a potential source of the most recent rapid rise in spending on prescription drugs. Even though the 1,000\% increases and more for drugs that have long lost patent protection raise important and legitimate concerns about how various segments of the industry are functioning, as has evidence of increasing consolidation in the prescription pharmaceuticals market, the broader data on the overall behavior of prices in the U.S. generic prescription pharmaceutical industry paints a different picture. 
The U.S. generic prescription pharmaceutical market continues to drive overall prices downward. Thus, our evidence suggests that overall affordability is not the main issue in the generic drug market and that this segment of the U.S. prescription drug market is not responsible for reported growth in prices and spending for prescription drugs overall.

Concerns have been raised about whether consumers are benefiting from the price declines because insurers and prescription benefit managers have been offering products that increasingly shift costs from insurers to consumers. Our evidence finds that consumers are experiencing more burdensome cost sharing and that in fact consumers are bearing a greater share of generic drug costs, yet on balance we find that consumers have experienced substantial overall price declines for generic drugs.

One important question raised by the differential patterns of price declines between overall and out-of-pocket consumer prices is how the benefits of price declines are being shared across the larger supply chain. Our CPI analysis shows that the full amount of the declines in generic prices is not being passed through to consumers. While a number of "back of the envelope" estimates have been made about the degree of passthrough of price reductions to consumers, ${ }^{9}$ we believe more systematic analysis of this phenomenon is needed. ${ }^{10}$ Moreover, our results also suggest a closer look at the workings of the entire generic drug supply chain (manufacturer, wholesaler, pharmaceutical benefit manager, insurer, and retailer) merits attention. 
${ }^{1}$ Office of the Inspector General, U.S. Department of Health and Human Services; Average Manufacturer Prices Increased Faster Than Inflation for Many Generic Drugs, Report A-06-00030, December 2015.

${ }^{2}$ Assistant Secretary for Planning and Evaluation, U.S. Department of Health and Human Services, Understanding Recent Trends in Generic Drug Prices, January 2016 ${ }^{3}$ Express Scripts, Express Scripts 2015 Drug Trend Report, March 2016

${ }^{4}$ Government Accountability Office, Part D Generic Prices Declined Overall, but Some Had Extraordinary Price Increases, Report GAO 16-706, 2016

5 Thompson A, S Karlin-Smith, Warren Bill would get feds into generic drug manufacturing, Politico, December 17, 2018

${ }^{6}$ Kaiser Family Foundation/HRET, Employer Health Benefits: Summary of Findings, 2018

${ }^{7}$ Berndt ER, Cutler DM, Frank RG, Griliches Z, Newhouse JP and Triplett JE, “Price Indexes for Medical Care Goods and Services: An Overview of Measurement Issues", chapter 4 in Cutler DM and Berndt ER, eds., Medical Output and Productivity, Chicago: University of Chicago Press for the National Bureau of Economic Research, 2001, pp. 1411-198.

${ }^{8}$ MEDPAC, March 2018 Report to Congress: Medicare Payment Policy, Chapter 14; March 2018

${ }^{9}$ Berkeley Research GROUP, The Pharmaceutical Supply Chain: Gross Expenditures by Stakeholders, 2017

${ }^{10}$ Sood N, T Shih, K Van Nuys, D Goldman, The Flow of Money Through The Pharmaceutical Distribution System, USC Schaeffer Center, June 2017 